\title{
Mổ xẻ lịch sử như là sự khởi động đến tương lai
}

\author{
Trần Đình Thiên \\ Tạp Chí Cộng Sản \\ (Bản điện tử)
}

Hà Nội, ngày 28 tháng 5 năm 2009

https:/tapchicongsan.org.vn/web/guest/thong-tin-ly-luan/-/2018/9348/\&quot;kinh-te-viet-nam--thang-tram-va-dot-pha\&quot;.aspx 


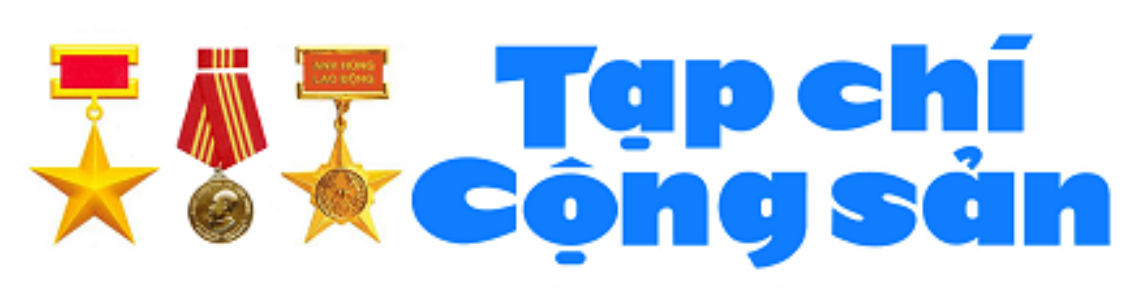

CƠ QUAN LÝ LUẬN CHÍNH TR! CỦA BAN CHẤP HÀNH

TRUNG ƯơNG ĐẢNG CộNG SẢN VIỆT NAM

๒งจาวาอ 中文 ENGLISH ESPAÑOL

\section{THÔNG TIN LÝ LUẬN}

\section{\&quot;Kinh tế Việt Nam - Thăng trầm và đột phá\&quot;}

TRẦN ĐİNH THIÊN

16:24, ngày 28-05-2009

Có thể nói "Mổ xẻ lịch sử như là sự khởi động đến tương lai" khi đọc cuốn sách "Kinh tế Việt Nam - Thăng trầm và đột phá"' do Nhà xuất bản Chính trị quốc gia mới ấn hành là công trình nghiên cứu một giai đoạn phát triển sôi động bậc nhất của nền kinh tế Việt Nam - giai đoạn Đổi Mới, chuyển từ nền kinh tế kế hoạch hóa tập trung sang nền kinh tế thị trường. Đây thực sự là một công trình nghiên cứu lịch sử kinh tế, gắn với một giai đoạn, do vị trí lịch sử khá đặc biệt của nó, được mổ xẻ, phân tích, đánh giá kỹ càng, không chỉ bởi các học giả Việt Nam mà còn của nhiều nhà nghiên cứu trên thế giới.

Mặc dù có chung chủ đề và chung mục tiêu với các công trình nghiên cứu lịch sử kinh tế Việt Nam hiện đại - nghiên cứu quá trình đổi mới kinh tế, cuốn sách của hai tác giả Phạm Minh Chính và Vương Quân Hoàng vẫn mang tính độc đáo, khác biệt và đặc sắc trên nhiều phương diện. Bởi lẽ:

Thứ nhất, trong cuốn sách này, lịch sử kinh tế Việt Nam, trong giai đoạn hào hùng nhất của nó, được mổ xẻ theo cách tiếp cận hiện đại, với những công cụ hiện đại. Đó là lịch sử vĩ mô của nền kinh tế thị trường (đúng hơn, của nền kinh tế chuyển đổi sang thị trường) chứ không phải của nền kinh tế "cây con, ngành nghề" như vẫn được thực hiện trong nhiều công trình nghiên cứu lịch sử kinh tế Việt Nam của các học giả Việt Nam cho đến nay. Sự phân tích hiện thực lịch sử kinh tế được các tác giả đặt trên nền tảng tri thức, lý thuyết và công cụ của môn kinh tế học hiện đại.

Thứ hai, lịch sử kinh tế quốc gia của một giai đoạn xác định không dài, được đặt trong không gian kinh tế 
thế giới và trong phông lịch sử dài hạn. Lịch sử diễn ra trong mạch thời gian và không gian liên tục chứ không hề bị cắt đoạn. Nhờ cách tiếp cận đó mà việc nhìn nhận, lý giải các sự kiện cụ thể trở nên có chiều sâu, có luận cứ chặt chẽ và xác đáng hơn.

Thứ ba, tính cập nhật cao độ các biến cố, sự kiện. Các tác giả không cố định lịch sử theo những mốc thời gian "cứng" mà mở biên ra cả hai đầu, nhất là đầu hướng tới tương lai. Có cảm tưởng rằng ngay cả khi cuốn sách đã lên khuôn in, các tác giả vẫn còn đến đề nghị dừng lại để bổ sung thêm vài sự kiện đáng đi vào lịch sử vừa mới xảy ra.

Cách kết nối lịch sử với hiện tại, coi hiện tại là lịch sử đang diễn ra như vậy giúp cuốn sách đề cập một cách tự nhiên các vấn đề thời sự nóng bỏng của nền kinh tế trong hai năm gia nhập WTO và chịu tác động mạnh mẽ của cuộc khủng hoảng kinh tế - tài chính toàn cầu "trăm năm có một" đang diễn ra một cách nóng hổi và sâu sắc. Ở góc độ này, cuốn sách của Phạm Minh Chính và Vương Quân Hoàng không còn là một cuốn sách sử mà là công trình nghiên cứu các vấn đề đương đại. Điều đó góp phần làm tăng thêm giá trị thực tiễn, tính gợi ý khoa học và đóng góp chính sách của công trình.

Thứ tư, trong nỗ lực đáp ứng yêu cầu khắt khe đặt ra công việc "chép sử", các tác giả của cuốn sách đã không chỉ làm công việc mô tả lịch sử theo cách biên niên, cũng không chỉ mổ xẻ các sự kiện theo lối khách quan dửng dưng vô cảm. Các nhận định, bình luận của cuốn sách mang tính phản biện cao, với một thái độ trách nhiệm đầy đủ. Nhìn giai đoạn lịch sử được đánh giá chung là "thành công ngoạn mục" không chỉ qua các sự kiện “đột phá" oai hùng mà quan trọng hơn - qua diễn biến "thăng trầm” gắn với những khó khăn, yếu kém và sai sót trong việc lựa chọn và thực thi một phương cách phát triển "chưa có tiền lệ lịch sử" bằng con mắt phê phán khoa học có thể coi là nét đặc sắc nổi bật nhất của cuốn sách này.

Về phần tôi, trong ý thức phản biện, thấy rõ rằng bên cạnh những ưu điểm thực sự đáng khen, cả về mặt nội dung khoa học lẫn về mặt phương pháp luận (mà tôi đánh giá cao nhất mặt này), cuốn sách vẫn còn những điểm khuyết thiếu cần được bổ túc, chỉnh sửa để nâng chất lượng lên đúng tầm chủ đề mà nó đề cập. Giá trị lịch sử - thời đại đối với dân tộc Việt Nam của công cuộc "lột xác", chuyển đổi một phương thức phát triển đã tồn tại hàng ngàn năm sang phương thức phát triển mà đa số nhân loại đang thực hiện, đó là điểm cần được nhấn mạnh hơn, làm rõ hơn qua các "thăng trầm" và "đột phá". Hoặc giả như định vị rõ hơn vai trò của các lực lượng chủ thể của quá trình này v.v..

Nhưng quả thật, những đòi hỏi này cũng vô cùng. Chúng cũng cần được bắt nguồn từ mỗi độc giả.

Điểm cuối cùng cần nói: cuốn sách này, cùng với một vài cuốn sách khác, chứng tỏ cần có cách tiếp cận mới, các công cụ mới và hệ tri thức mới để mổ xẻ, phân tích các quá trình thực tiễn. Bản thân cuốn sách được coi là một sự khởi động thật sự, rất đáng trân trọng cho quá trình đó. Đẩy mạnh hơn quá trình này là một cách, một nội dung hội nhập quốc tế - hội nhập khoa học, đồng thời là cách thúc đẩy sự phát triển 
trong hội nhập của nền kinh tế nước ta. Vì tất cả những lẽ đó "Kinh tế Việt Nam - thăng trầm và đột phá" là cuốn sách cần và nên đọc./.

\section{BÀI CÙNG CHỦ ĐỀ}

Thực trạng dân số Việt Nam năm 2008 (28/05/2009)

Cải cách giáo dục ở Hàn Quốc (28/05/2009)

Thủ tướng Nguyễn Tấn Dũng bắt đầu thăm chính thức Hàn Quốc (28/05/2009)

Tổng giá trị vốn ODA 5 tháng đầu năm 2009 đạt 1.467,47 triệu USD (27/05/2009)

Thông cáo số 7 kỳ họp thứ năm, Quốc hội khóa XII (27/05/2009)

Khai mạc Hội nghị Bộ trưởng ASEAN về Phát triển nông thôn và xóa đói, giảm nghèo lần thứ 6 (27/05/2009)

Ứng dụng tạm thời không có. 


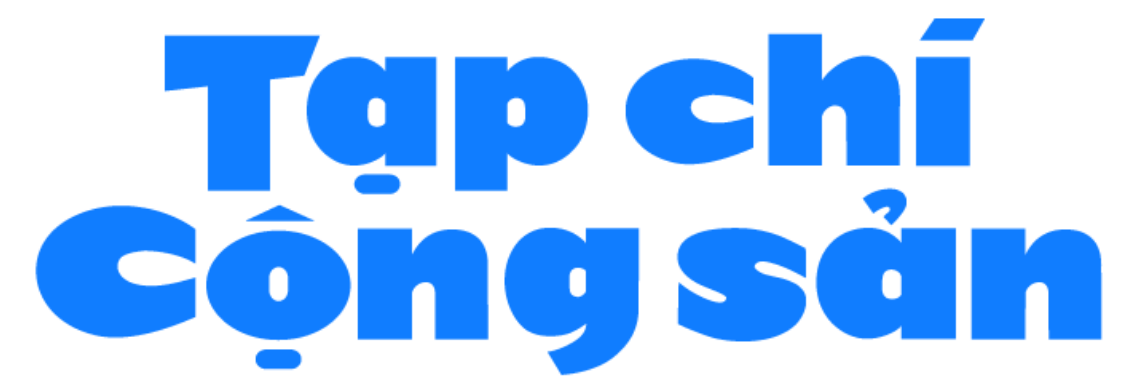

NHỮNG CHẶNG ĐƯỜNG PHÁT TRIỂN

\section{TỔNG BIÊN TẬP: PGS,TS. ĐOÀN MINH HUẤN}

\section{Bộ Biên tập:}

Địa chỉ: Số 28, Trần Bình Trọng - thành phố Hà Nội

Điện thoại: 02439429753 - Fax: 02439429754

Email: tapchicongsandientu@tccs.org.vn

\section{Cơ quan Thường trực tại miền Trung - Tây Nguyên:}

Số 26 Trần Phú, thành phố Đà Nẵng

Điện thoại: (080) 51 301; Fax: (080) 51303

\section{Cơ quan Thường trực tại miền Nam:}

Địa chỉ: Số 19 Phạm Ngọc Thạch,

Thành phố Hồ Chí Minh

Điện thoại: (080) 84083; Fax: (080) 84081

\section{Văn phòng đại diện tại thành phố Cần Thơ:}

Địa chỉ: Số 86 Nguyễn Trãi, thành phố Cần Thơ

Điện thoại/Fax: (0710)6250868

\section{- HÀNH CHÍNH ĐIỆN TỬ 4}

LIÊN HẸ GỬ BÀI VÀ ĐÓNG GÓP Ý KIẾN

LIÊN HẸ QUẢNG CÁO: 08046138

@Bản quyền thuộc về Tạp chí Cộng sản

Giấy phép số 436/GP-BTTTT ngày 14-10-2019 của Bộ Thông tin và Truyền thông. Mọi hành động sử dụng nội dung đăng tải trên Tạp chí Cộng sản điện tử tại địa chỉ www.tapchicongsan.org.vn phải dẫn nguồn và có sự đồng ý bằng văn bản của Tạp chí Cộng sản 


\section{Tài liệu tham khảo:}

Phạm Minh Chính, Vương Quân Hoàng. (2008). Bối cảnh tài chính Việt Nam 1997-1998 và 2007-2008: khoảng cách và biến đổi. Nghiên cứu Kinh tế, 48(7), 3-24.

Phạm Minh Chính, Vương Quân Hoàng (2008) Bảy dấu hiệu cảnh báo cần lưu ý để ổn định nền tài chính quốc gia. Tạp Chí Cộng Sản; 15/5/2008 (Bản điện tử). URL:

$<$ http://www.tapchicongsan.org.vn/Home/Nghiencuu-Traodoi/2008/1420/Bay-dau-hieucanh-bao-can-luu-y-de-on-dinh-nen.aspx>

Phạm Minh Chính, Vương Quân Hoàng. (2009). Kinh tế Việt Nam: Thăng trầm và đột phá. Nxb Chính trị Quốc gia, Hà Nội. 